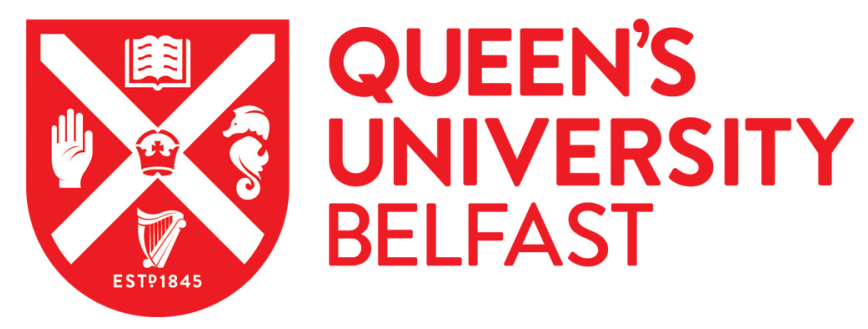

\title{
Low molecular weight gelators (LMWGs) for ionic liquids: the role of hydrogen bonding and sterics in the formation of stable low molecular weight ionic liquid gels
}

McNeice, P., Zhao, Y., Wang, J., Donnelly, G., \& Marr, P. (2017). Low molecular weight gelators (LMWGs) for ionic liquids: the role of hydrogen bonding and sterics in the formation of stable low molecular weight ionic liquid gels. Green Chemistry, 19, 4690-4697. https://doi.org/10.1039/C7GC02053H

Published in:

Green Chemistry

Document Version:

Peer reviewed version

Queen's University Belfast - Research Portal:

Link to publication record in Queen's University Belfast Research Portal

Publisher rights

(c) 2017 Royal Society of Chemistry. This work is made available online in accordance with the publisher's policies. Please refer to any applicable terms of use of the publisher.

\section{General rights}

Copyright for the publications made accessible via the Queen's University Belfast Research Portal is retained by the author(s) and / or other copyright owners and it is a condition of accessing these publications that users recognise and abide by the legal requirements associated with these rights.

Take down policy

The Research Portal is Queen's institutional repository that provides access to Queen's research output. Every effort has been made to ensure that content in the Research Portal does not infringe any person's rights, or applicable UK laws. If you discover content in the

Research Portal that you believe breaches copyright or violates any law, please contact openaccess@qub.ac.uk. 


\title{
Low Molecular Weight Gelators (LMWGs) for Ionic Liquids: The Role of Hydrogen Bonding and Sterics in the Formation of Stable Low Molecular Weight Ionic Liquid Gels.
}

\author{
Peter McNeice, Yingying Zhao, Jianxun Wang, Gerald F. Donnelly and Patricia C. Marr*
}

School of Chemistry and Chemical Engineering, The Queen's University of Belfast,

The David Keir Building, Stranmillis Road, Belfast, BT9 5AG, United Kingdom.

Tel:+44 (0) 2890974740.

Email:p.marr@qub.ac.uk.

Keywords: Low Molecular Weight Gelators, LMWGs, ionic liquid, Gel, lon gel (ionogel), solvent parameters, Kamlet-Taft.

\begin{abstract}
Low molecular weight gelators capable of forming a gel with an ionic liquid are rare. We report the ability of 3 sugar based gelators from renewable resources (derived from isosorbide and mannitol) to form gels with 21 ionic liquids comprising a range of cations and anions that are commonly applied in a variety of technologies. It was found that the combined consideration of Kamlet-Taft values with ionic liquid size and shape gives a useful predictor of successful gel formation.
\end{abstract}

\section{Introduction}

A gel can be defined as a 3-dimensional structure composed of a heterogeneous 2 phase system comprising a liquid (dispersed phase) within a solid (continuous phase). The structures of gels are diverse and they can be formed in many ways and from many liquid and solid combinations. ${ }^{1}$ Supramolecular self-assembly of 3D networks of low molecular weight gelators (LMWGs) usually occurs through physical interactions such as $\pi$ stacking, hydrogen bonding or Van der Waals interactions. These come together to form a structure that is capable of holding a liquid within its construction. ${ }^{2,3,4}$ Gels of this type have been found to have diverse applications in food, cosmetics, batteries, membranes, catalysts, medical devices and environmental remediation ${ }^{5}$ (oil spills, metal removal). The design of new LMWGs is a challenging task, and building an understanding of the interactions that drive gel formation is an essential prerequisite. Interactions between the gelator molecules and between the liquid component (solvent) and the gelator all have to collaborate in order to achieve a gel state. Using solvent parameters ${ }^{6}$ and solubility parameters ${ }^{7,8}$ could aid the rational design of gels. Examples of ionic liquid gels based on LMWGs are uncommon. One of the earliest observations of ionic liquid LMWG gel formation occurred when an ether containing IL was 
used as a solvent for amide-group-enriched glycolipids. ${ }^{9}$ IL gelation was reported for a cholesterol based structure containing a glucopyranosyl unit. The LMWG itself was insoluble in the ionic liquid so a co-solvent needed to be added, (acetone in this example), the gel formed as the co-solvent evaporated. The use of a co-solvent is a disadvantage due to safety concerns, environmental impact, and the potential to introduce further impurities. ${ }^{10}$ Two excellent gelators for ILs (imadizolium, pyridinium, pyrazolidinium, piperidinium, morpholinium and ammonium salts.), both based on aspartame were previously reported. ${ }^{11,12}$ In another example 12-hydroxystearic acid has been observed to act as an LMWG to form a gel with 1-hexyl-3-methylimidazolium bistriflimide, $\left(\left[\mathrm{C}_{6} \mathrm{MIM}\right]\left[\mathrm{NTf}_{2}\right]\right) .{ }^{13}$ Bis(4-octanoylaminophenyl) ether, bis(4-octanoylaminophenyl) methane and 2,4bis(octanureido) toluene were found to gel ionic liquid $\left(\left[\mathrm{C}_{4} \mathrm{mim}\right]\left[\mathrm{PF}_{6}\right]\right)$ and the electrochemical properties measured for the ionic liquid gels were similar to those of the pure ionic liquid. ${ }^{14}$ Quasisolid-state materials were constructed using the LMWG 1,3:2,4-di-O-benzylidene- $D$-sorbitol (DBS) and used in DSSC solar cells. ${ }^{15}$ Organometallic gelators ${ }^{16}$ have been shown to gel a range of ionic liquids (imadizolium pyridinium, pyrazolidinium, piperidinium and ammonium salts). Other classes of ionic liquid gels are discussed elsewhere. ${ }^{17}$

Despite wide acceptance that hydrogen bonding occurs in ionic liquids, it is relatively poorly understood. ${ }^{18}$ This stems from the fact that the hydrogen bonding interactions in ionic liquids are coupled with ionic interactions, making them difficult to measure. Kamlet-Taft parameters are an easily accessible method of quantifying the bulk properties that result from hydrogen bonding. ${ }^{19}$ These empirical polarity Kamlet-Taft parameters are widely measured for ionic liquids. ${ }^{20,21}$ This multiparameter methodology is broken down into polarizability, $\pi^{*}$, hydrogen bond acceptance, $\beta$, and hydrogen bond donation, $\alpha .{ }^{19} \beta$ and $\alpha$ values are used in this study as they relate more closely to hydrogen bonding than $\pi^{*}{ }^{*} 19,27 \beta$ values are the most accurate of the parameters as they are measured by testing the ionic liquid against two probe solvents, one known to be hydrogen bonding. Studies have shown that the $\beta$ value depends largely on the anion, varying the cation does not greatly affect the $\beta$ value. ${ }^{22} \alpha$ values are the most variable of the Kamlet-Taft parameters as they are not measured directly but based on the $\mathrm{E}_{\mathrm{T}}{ }^{30}$ and $\pi^{*}$ values. Despite the variations that occur, it has largely been shown that the $\alpha$ value is dominated by the cation, particularly those cations with traditional hydrogen bond donor species attached, such as $\mathrm{OH}$ groups. ${ }^{22}$

We report the formation of low molecular weight gels with 21 different ionic liquids. 3 LMWGs are presented that are capable of entrapping a diverse range of ionic liquids. In order to further understand what drives the gel formation, we explored the role of hydrogen bonding and sterics in determining the effects of changing the cation and anion components. Previous literature suggested 
that the anion component had a more significant effect. ${ }^{23,12,24}$ Firstly we considered if the $\mathrm{H}$ bonding acceptor/H bonding donor values from Kamlet-Taft ${ }^{19}$ measurements could be used to rationalise gelation ability. We found that Kamlet-Taft parameters gave an excellent insight into the ability of an ionic liquid to form a low molecular weight gel. Secondly we wanted to ascertain at what level steric effects could inhibit gel formation, as this could also be a useful predictor of what ionic liquids are suitable for a LMWG ionic liquid gel system. The focus was on LMWGs that come from renewable resources, utilising gelators from non-hazardous sugars such as isosorbide ${ }^{25}$ and $D$ mannitol ${ }^{26}$ (Figs. 1,2). LMWGs derived from sugars have been shown to gel a wide range of solvents from water to oils, this may be due to formation of strong hydrogen bonds as such interactions have been identified (by NMR and IR) as a key factor in gel formation. ${ }^{26,12}$ The sugars also impart homochirality which is often important in gel formation. ${ }^{27}$

Of the gels presented here several have been successfully formulated from functional ionic liquids which have shown promise in diverse applications. For example $[\mathrm{BMIM}][\mathrm{OAc}]: \mathrm{CO}_{2}$ uptake, [EMIM] [NTf 2 ]: electrochemical applications, electrocatalysis, [BMIM] $\left[\mathrm{HSO}_{4}\right],[\mathrm{TEAPS}]\left[\mathrm{NTf}_{2}\right]^{28}$ : acidic catalytic membranes. In some of these applications the ionic liquid could be made more easily applied in the gel state. Thermally reversible gels of this nature have the potential to be easily disassembled allowing for the full recovery of the ionic liquid post application.

\section{Results and discussion}

In this study three low molecular weight gelators based on sugar molecules were explored, these were synthesised according to literature procedures (Figs. 1, 2) ${ }^{25,26}$ Craythorne et al ${ }^{25}$ introduced isosorbide based gelator $\mathbf{1}$, which was shown to gel water and a range of solvents from alcohols to toluene. Mannitol based gelators $\mathbf{2}$ and $\mathbf{3}$ were shown by Vidyasagar et $a{ }^{26}$ to be extremely efficient gelators for a wide variety of organic solvents and oils from sunflower to silicone oils. ${ }^{26}$ In some cases forming optically clear gels at remarkably low concentrations $0.2 \mathrm{wt} \% .31$ different ionic liquids were chosen for gel testing, 21 of which were successfully gelled (ESI Tables S1, S2). The ionic liquids represent a wide range of common cation (Fig. 9) and anion (Fig. 5) combinations. 


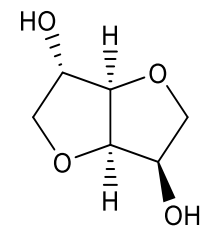

Isosorbide

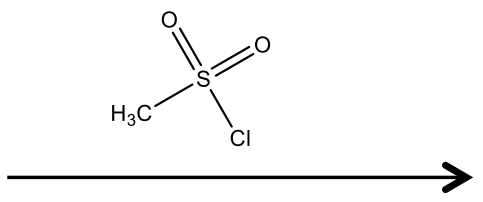

Pyridine, $0^{\circ} \mathrm{C}-50^{\circ} \mathrm{C}$

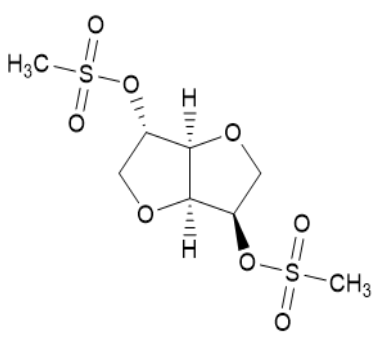

2,5-di-O-methanesulfonyl-1,4:3,6-dianhydro-D-sorbitol (Gelator 1)

Fig. 1. Literature synthesis of an isosorbide derived LMWG (Gelator 1 ). ${ }^{25}$
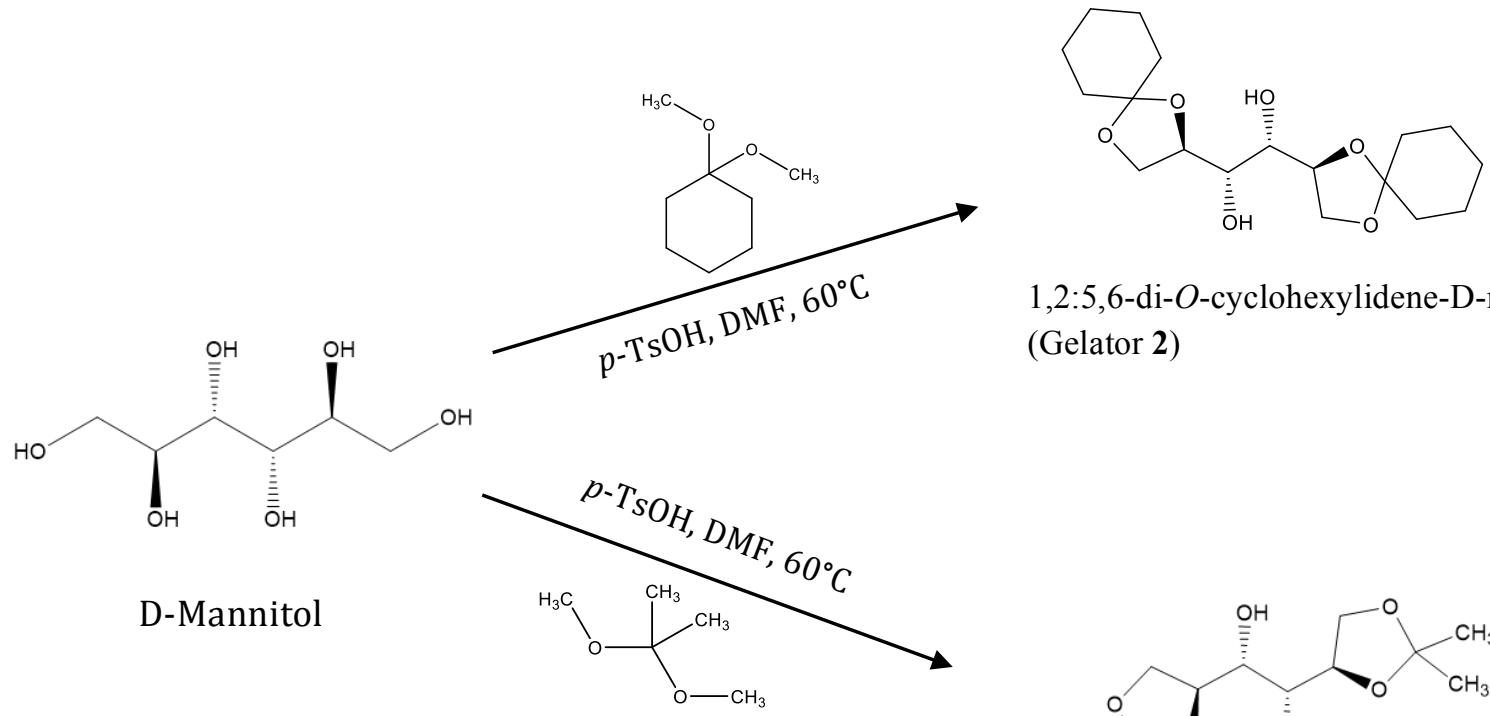

1,2:5,6-di-O-cyclohexylidene-D-mannitol (Gelator 2)

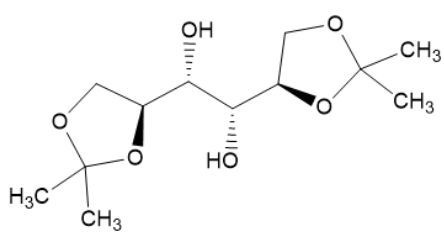

1,2:5,6-di- $O$-isopropylidene-D-mannitol (Gelator 3)

Fig. 2. Literature synthesis of D-mannitol derived LMWGs (gelator 2 and 3). ${ }^{26}$

LMWGs 1, 2 and 3 gel a wide range of ionic liquids. These include those with imidazolium, ammonium, phosphonium and pyridinium cations along with a range of anions coupled to the $[B M I M]^{+}$cation (ESI Tables S1 and S2). All LMWGs tested in this study were soluble in the ionic liquids, with some ionic liquids dissolving the LMWGs at room temperature without sonication and some after sonication and heating. Dissolution of the LMWG in the ionic liquid is a necessary step in 
the formation of molecular gels. A common method used in molecular gel formation, is the heating/cooling method. In one example Shinkai and co-workers ${ }^{10}$ required a co-solvent acetone to dissolve their gelator in order to form gels. Hanabusa et. al. ${ }^{12}$ tested 12 possible LMWGs to gel ionic liquids and found only the 2 which were soluble allowed gel formation. Sonication was carried out during all tests in this study to aid dissolution of solids ${ }^{29}$ before heating/cooling, irrespective of whether the gelator was initially soluble in the IL or not. A detailed study of LMWG solubility in individual ionic liquids was not carried out here. Fig 3 shows the appearance of the gels made with $\left[\mathrm{N}_{2228}\right]\left[\mathrm{NTf}_{2}\right]$ and [EMIM] $\left[\mathrm{NTf}_{2}\right]$. Photographs of all the gels formed are in the Supplementary Information (ESI Fig. S2).

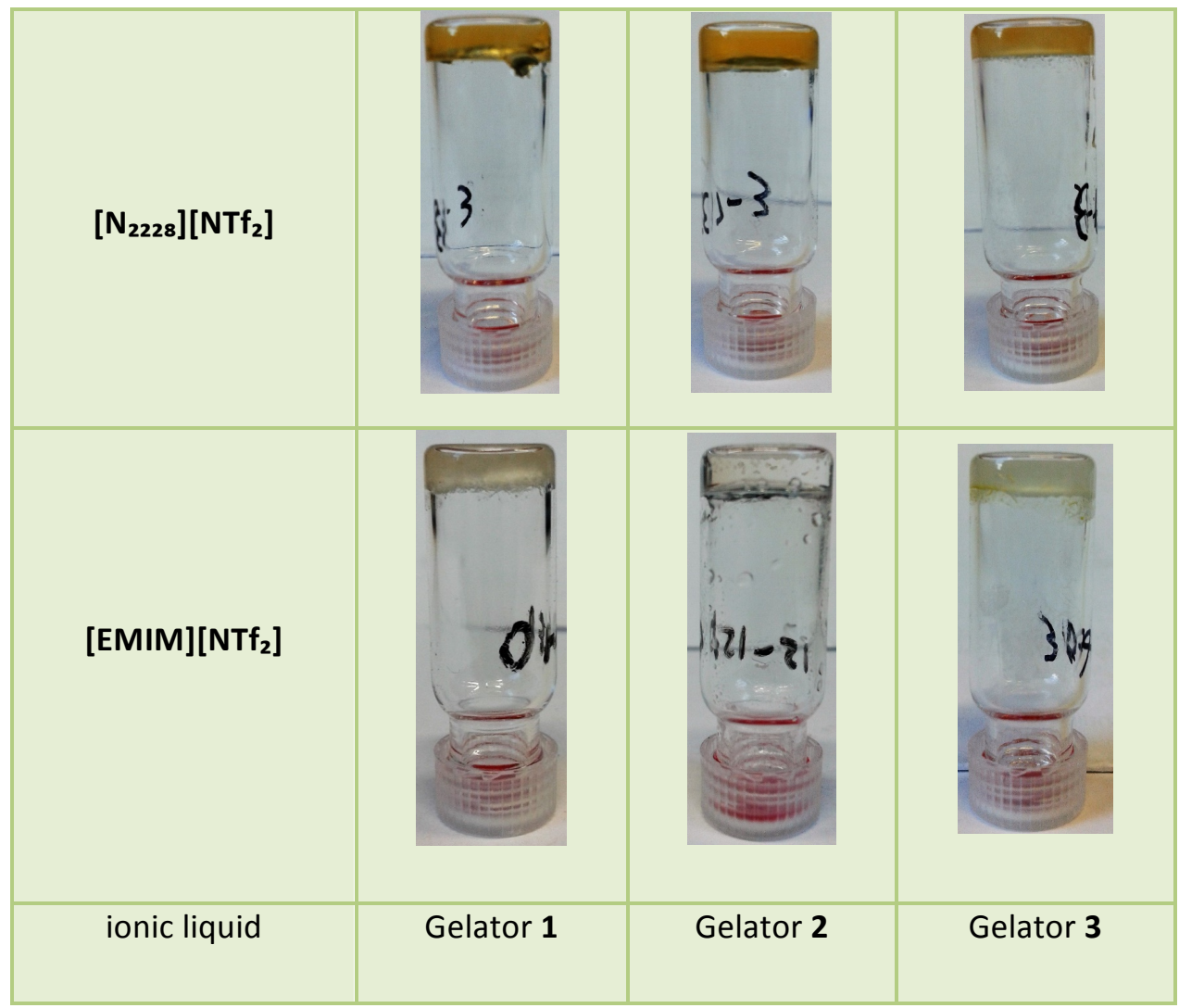

Fig. 3. low molecular weight ionic liquid gels.

The colour varied, and was dependent on the initial colour of the ionic liquid, and the gels ranged from clear, to opaque/cloudy. The cloudiness of the gel may be attributed to a precipitation of larger crystals of LMWG as the ionic liquid cooled. Opaque gels could frequently be made clear by cyclic heating, (successive heat/cool cycles). Gel stability was assessed by tube inversion "the least ambiguous method". ${ }^{30}$ If the gel did not flow and showed no signs of leakage it was deemed stable (stable to inversion). The gels had good stability at room temperature with most of the gels still stable to inversion several months later, even at low wt. \% ( 2 wt. \%). 20 ionic liquids formed gels which were stable a year after forming. This compares to other groups who reported their gels 
stable for several months, ${ }^{26}$ and two years. ${ }^{12}$ The sol-gel transition temperature (gel temperature) was found to be around $80^{\circ} \mathrm{C}$ for gels formed with gelator $\mathbf{2}$ (ESI S4.2 DSC). This is comparable to the gel temperature found for 2 in the literature ${ }^{26}$ (Heptane $81^{\circ} \mathrm{C}$, Hexane $84^{\circ} \mathrm{C}$ ). The traces of [EMIM] $\left[\mathrm{NTf}_{2}\right]$ and $[\mathrm{BMIM}]\left[\mathrm{NTf}_{2}\right]$ with 2 are largely identical. The endotherm at $80{ }^{\circ} \mathrm{C}$ represents the sol-gel transition. This is due to the reversibility of molecular gel formation and occurs because the gel structure is held by physical forces such as hydrogen bonding and van der Waals' interactions. An exothermic peak at $-22^{\circ} \mathrm{C}$ for $[\mathrm{BMIM}]\left[\mathrm{NTf} f_{2}\right]$ and $-50^{\circ} \mathrm{C}$ for $[\mathrm{EMIM}]\left[\mathrm{NTf}_{2}\right]$ is due to crystallisation. This along with the lack of a glass transition endotherm indicates the materials are not amorphous but have the ordered 3D structure of a gel. The low temperature endotherms can be attributed to breakdown of the crystal structure, with multiple peaks being a result of multiple arrangements of different thermal stabilities ${ }^{31}$. TGA analysis indicates that in general the gels are more stable at higher wt. \% of gelator, with the $[\mathrm{BMIM}]\left[\mathrm{NTf}_{2}\right]$ gel decomposing at a higher temperature with $10 \mathrm{wt}$. \% 2. than with 5 wt. \% (ESI S4.1 TGA). The thermal stabilisation of the IL was observed on dissolution of the LMWG and was not dependent on gel formation. This is seen by comparing the TGA of bulk [EMIM] $\left[\mathrm{NTf}_{2}\right]$ with the TGA of [EMIM] $\left[\mathrm{NTf}_{2}\right]$ containing $2 \mathrm{wt}$. \% 2 (ESI S4.1 TGA). The $\mathrm{T}_{\text {onset }}$ of the gelled ionic liquid is over $100^{\circ} \mathrm{C}$ higher than the ionic liquid with no LMWG. A similar increase in bulk ionic liquid stability was recently seen in silica based ionic liquid gels formed via the sol-gel route. ${ }^{32} \mathrm{~A}$ minority of the samples were found to resist gel formation. Any factor which prevents the formation of the 3D network will prevent the formation of a gel. In an organic solvent this disruption could be caused by steric or electronic factors. With an ionic liquid the effect of cation, anion (complicated by the fact that there is contribution from both the cation and anion) steric limitations and ion combinations could all affect gelation. In an ionic liquid the cation is considered to be the hydrogen bond donor the anion a hydrogen bond acceptor. The ring (imidazole) contributes to $\pi$ Stacking while addition of an alkyl chain can yield Van der Waals interactions.

\section{The effect of the anion on gel formation.}

To study the effect of the anion on the gelation properties of the ionic liquids, a range of anions were studied keeping the cation $[\mathrm{BMIM}]^{+}$the same. The anion was found to have a profound effect on gelation. Anions that were able to strongly accept hydrogen bonds, such as $\mathrm{Br}^{-}$, did not gel at low wt. \% of 2. The anion, being a large component of the solvent, is in excess. This allows it to saturate the hydrogen bond donors in the gelator molecules, preventing them from forming interactions with each other. When this occurs it leads to solutions, the ionic liquid solubilises the gelator but does not form a gel. The anions with the lowest $\beta$ values are $\left[\mathrm{BF}_{4}\right]^{-},\left[\mathrm{NTf}_{2}\right]^{-}$and $\left[\mathrm{PF}_{6}\right]^{-}$(Fig. 5), with values of $0.370 .23^{29}$ and $0.21^{33}$ respectively. Ionic liquids with these anions formed gels with the lowest 
concentration of gelator $\mathbf{2}$ (2 wt. \%). No other anions in combination with [BMIM] $]^{+}$formed gels at 2 wt \% (Fig. 4).

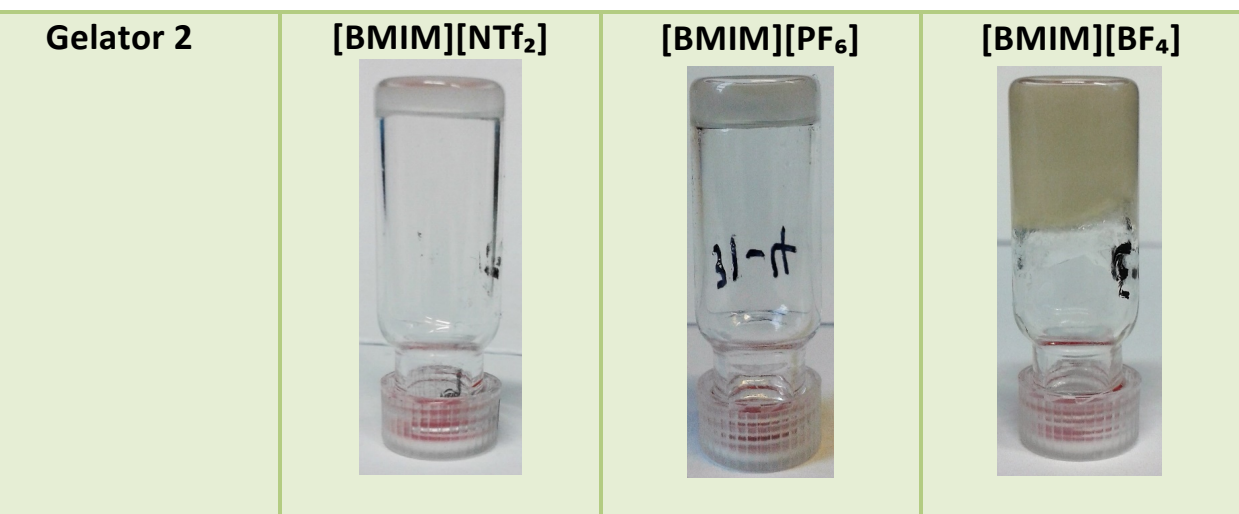

Fig. 4. Gels formed with $[\mathrm{BMIM}]$ cation with $\left[\mathrm{NTf}_{2}\right]\left[\mathrm{PF}_{6}\right]$ and $\left[\mathrm{BF} F_{4}\right]$ with $\mathbf{2}$.

The anions with moderately high $\beta$ values such as [OTf] $]^{-}(0.57)^{34}\left[\mathrm{MeSO}_{4}\right]^{-}(0.67)^{35}$ and $\left[\mathrm{HSO}_{4}\right]^{-}$ (Kamlet-Taft similar to $\left[\mathrm{MeSO}_{4}\right]^{-}$) could not form gels at $4 \mathrm{wt}$ \% 2 but did gel at $10 \mathrm{wt}$. \%. for ILs of anions with higher $\beta$ values, a higher concentration of gelator was required to compete with the anion in order to form the gel state. The analysis of anions (ESI table S1) shows that those anions with the highest $\beta$ values such as $[\mathrm{SCN}]^{-}(0.71),[\mathrm{OAc}]^{-}(0.85)$, and $\mathrm{Br}^{-}(0.87)^{34}$ were not able to form gels even at $10 \mathrm{wt} \%$ of $\mathbf{2}$. These anions are extreme hydrogen bond acceptors, able to saturate the hydrogen bond donors of the gelator even when the wt. \% of gelator increases. A $\beta$ value could not be obtained for the docusate anion. However, comparing it to the high values of other similar long chain alkyl-sulfonates ${ }^{36}$ would indicate that its $\beta$ value would also be very high. This high $\beta$ value, combined with its steric bulk, may account for its inability to form gels at $10 \mathrm{wt}$. \%. This effect was observed previously using gelators $\mathbf{2}$ and $\mathbf{3}$, with oils (sunflower, palm, silicon and paraffin (c15-40). ${ }^{26}$ Oils which compete for hydrogen bonds did not gel, or formed weak gels. The majority of ionic liquid containing gels have the IL as the Liquid (continuous) phase. There are some notable examples of ILs and organic salts (diimidazolium salts) being used as gelators for solvents (dispersed phase) organic solvents and water (organogels, hydrogels). ${ }^{23}$ When investigating the ability of some diimidazolium salts to form gels with a variety of solvents (alcohols, acetonitrile, toluene acetone and water) they noted that the nature of the anion had a bigger effect on gel formation than the cation and that dianions further enhanced gel formation. It has also been postulated that ionic liquids or organic salts only gel organic solvents when the anion and cation interact well. ${ }^{23}$ Even though in this case organic salts/ionic liquids are being used as the gelator (continuous phase, solid component) it has been noted that there is an effect involving the choice of cation and anion for successful gel formation. The interaction between the cation and the anion in $[\mathrm{BMIM}][\mathrm{Br}]$ is stronger than in many ionic liquids due to the $\mathrm{Br}^{-}$ion's small size. As such it is a solid at R.T. with melting point of $78{ }^{\circ} \mathrm{C}^{37}$ 
When $[\mathrm{BMIM}][\mathrm{Br}]$ is heated with a LMWG it melts and does not reform a solid but instead a very viscous liquid. This could indicate that there is a disruption of the interactions between the cation and anion, most likely caused by interaction between the anion and LMWG molecules.

Computational studies ${ }^{37}$ show that while coulombic interactions are the main force attracting the cation and anion, there are significant interactions due to physical forces such as $\pi$-stacking, hydrogen bonding and partial charge transfer. They show that the greater the partial charge transfer from the anion to the cation in $[\mathrm{BMIM}][\mathrm{Cl}]$, the more stable a conformation is formed. ${ }^{38}$ The exact influences of the steric disruption of the anion were not determined here. However, the results do indicate that for these gelators 1-3 the size of the anion has a smaller influence on gelation than the

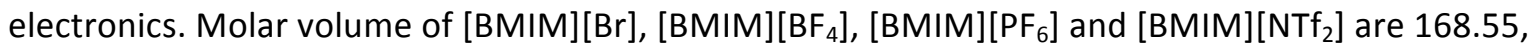
$189.93,208.96$ and $291.22 \mathrm{~mol}^{-1} \mathrm{~cm}^{-3}$ respectively (ESI Table S3). This is a useful quantification of steric bulk of ionic liquids. $\mathrm{Br}^{-}$is the smallest anion and yet it did not form a gel, whereas much larger anions such as $\left[\mathrm{BF}_{4}\right]^{-},\left[\mathrm{PF}_{6}\right]^{-}$and $\left[\mathrm{NTf}_{2}\right]^{-}$(Fig. 5) all gelled. In addition, ILs with the larger $\left[\mathrm{NTf}_{2}\right]^{-}$ion gelled at a lower wt. \% of $\mathbf{2}$ than ILs with the smaller $\left[\mathrm{BF}_{4}\right]^{-}$and $\left[\mathrm{PF}_{6}\right]^{-}$ions (Fig.5), indicating that a higher $\beta$ value is indicative of inhibition of gelation but anion size does not appear to have such a large effect (ESI Table S1, S2).

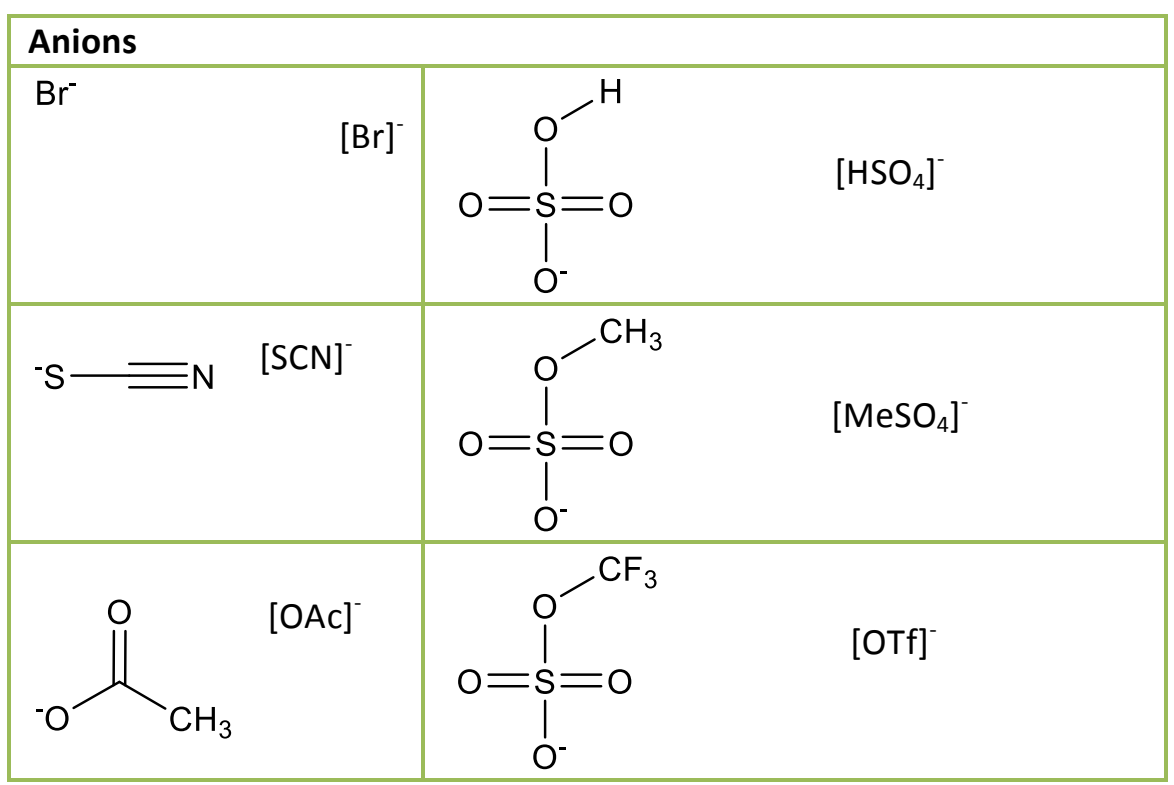




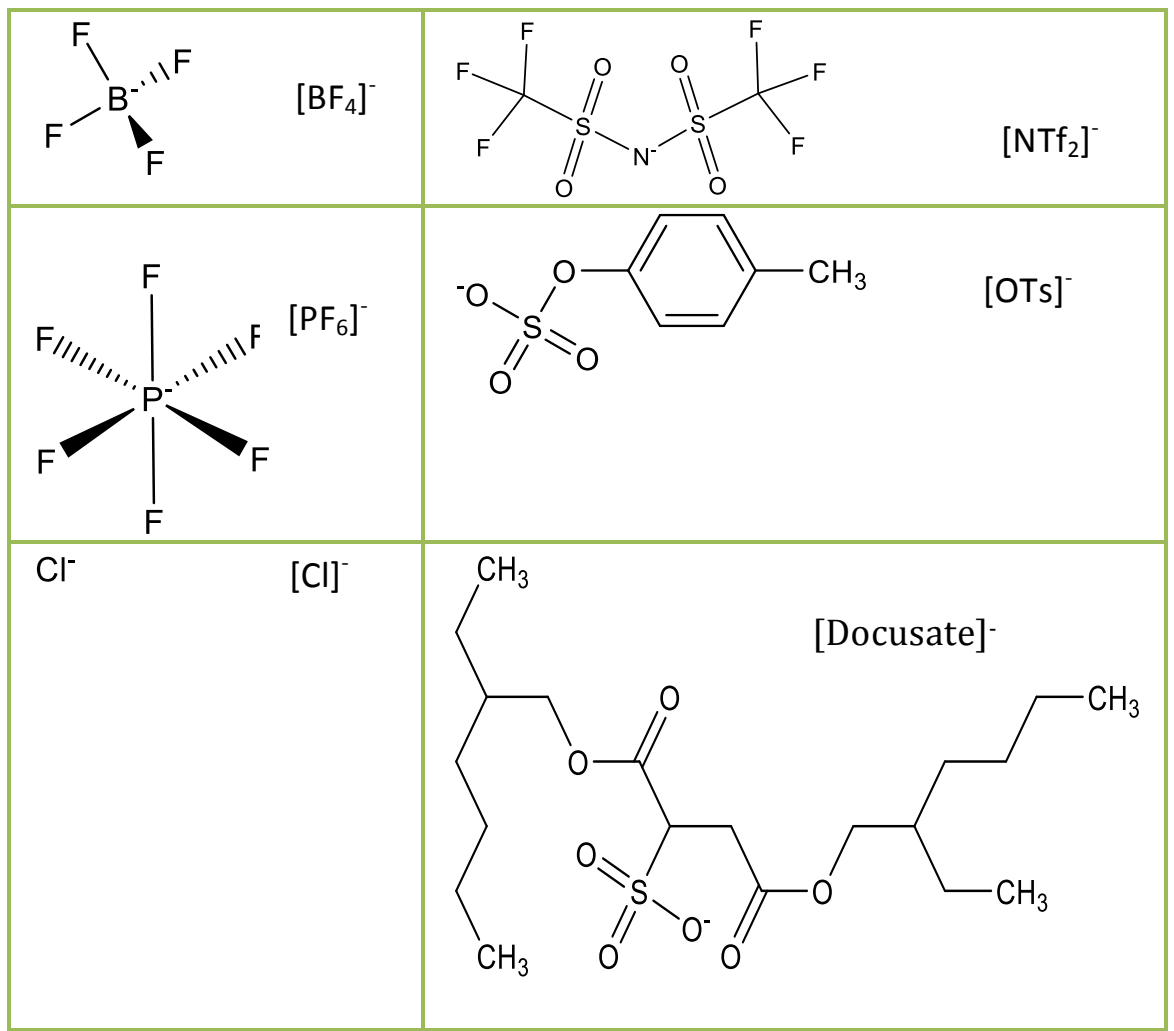

Fig. 5. Range of anions used.

\section{The effect of the cation on gelation.}

As with the anion, steric factors appear to play a smaller role than the electronic factors. However unlike the anion, the cation effect is generally dominated by hydrogen bond donation indicated by the $\alpha$ value (ESI Table S2). A range of cations were explored (Fig. 9). One example is seen by comparing [Po1MIM] $\left[\mathrm{NTf}_{2}\right]\left(\alpha 0.91^{39}, \mathrm{~V}_{\mathrm{m}} 273.60\right)$ with $\left[\mathrm{C}_{6} \mathrm{MIM}\right]\left[\mathrm{NTf} f_{2}\right]\left(\alpha 0.65^{33}, \mathrm{~V}_{\mathrm{m}} 326.58\right)$ $\left.\left[\mathrm{C}_{8} \mathrm{MIM}\right]\left[\mathrm{NTf}_{2}\right](\alpha \quad 0.6)^{22}, \mathrm{~V}_{\mathrm{m}} 360.20\right)$ and $\left[\mathrm{C}_{12} \mathrm{MIM}\right]\left[\mathrm{NTf}_{2}\right]\left(\mathrm{V}_{\mathrm{m}}\right.$ 428.69) (ESI Table S3). What is significantly different about these ionic liquids is that in [Po1MIM] $\left[\mathrm{NTf}_{2}\right]$ there is an $\mathrm{OH}$ group on the end of the alkyl chain compared to a methyl group on the others (Fig. 9). [Po1MIM] $\left[\mathrm{NTf}_{2}\right]$ is the smallest of these ionic liquids having the shortest chain length and yet it did not gel at $4 \mathrm{wt}$. \% of $\mathbf{2}$. On the other hand, the much larger $\left[\mathrm{C}_{6} \mathrm{MIM}\right]\left[\mathrm{NTf}_{2}\right],\left[\mathrm{C}_{8} \mathrm{MIM}\right]\left[\mathrm{NTf}_{2}\right]$ and $\left[\mathrm{C}_{12} \mathrm{MIM}\right]\left[\mathrm{NTf} f_{2}\right]$ (Fig. 6) all gelled with 4 wt. \% 2. $\left[\mathrm{C}_{6} \mathrm{MIM}\right]\left[\mathrm{NTf}_{2}\right]$ formed a gel at (2 wt. \% 2). This is likely to be from the hydrogen bonding nature of the respective ionic liquids. [Po1MIM] $\left[\mathrm{NTf}_{2}\right] \alpha$ value of $0.91^{39}$ was more difficult to gel, requiring higher concentrations of LMWG. This can be rationalised due to the disruptive hydrogen bonding interaction from the $\mathrm{OH}$ group on the cation. $\left[\mathrm{C}_{6} \mathrm{MIM}\right]\left[\mathrm{NTf}_{2}\right](\alpha 0.65),{ }^{33}$ $\left[\mathrm{C}_{8} \mathrm{MIM}\right]\left[\mathrm{NTf}_{2}\right](\alpha 0.60)$ and $\left[\mathrm{C}_{12} \mathrm{MIM}\right]\left[\mathrm{NTf}_{2}\right]$ ( $\alpha$ unavailable) have no OH groups, and as such their $\alpha$ values are considerably lower than [Po1MIM] $\left[\mathrm{NTf}_{2}\right](\alpha$ 0.91) and as such they do not disrupt formation of the 3D network in the same way (Fig. 7). 


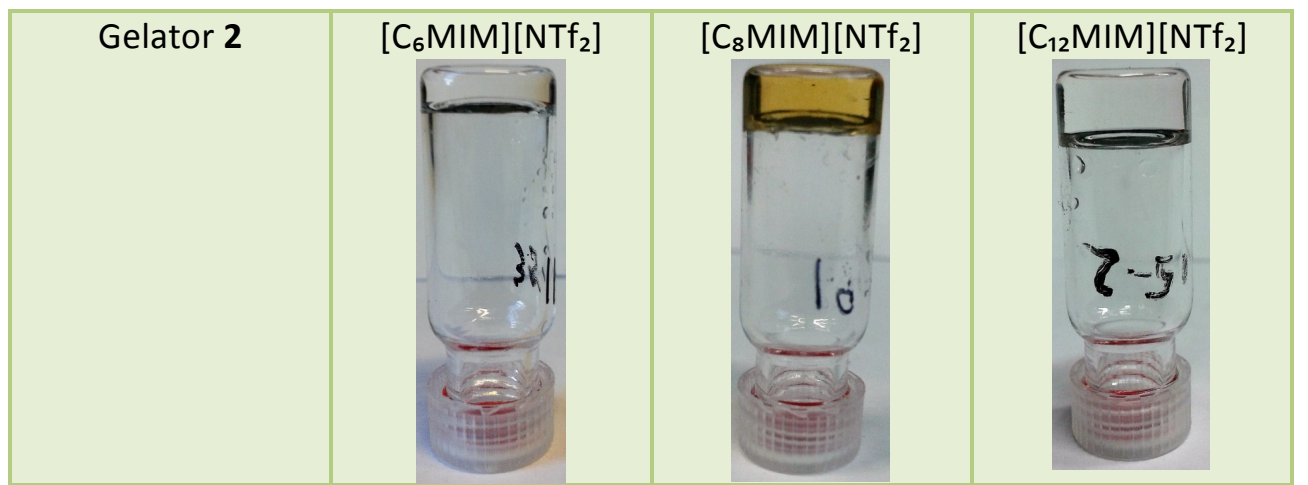

Fig. 6. Gels formed with $\left[\mathrm{NTf}_{2}\right]$ anion and $\left[\mathrm{C}_{6} \mathrm{MIM}\right]\left[\mathrm{NTf} f_{2}\right],\left[\mathrm{C}_{8} \mathrm{MIM}\right]\left[\mathrm{NTf} f_{2}\right],\left[\mathrm{C}_{12} \mathrm{MIM}\right]\left[\mathrm{NTf} f_{2}\right]$ cations with gelator 2.

The fine balance between hydrogen bonding ability and gelation is also seen by considering two pairs of ionic liquids. Comparing $\left[\mathrm{C}_{4} \mathrm{Py}\right]\left[\mathrm{NTf}_{2}\right](\alpha 0.54)^{33}(\mathrm{Vm} 289.14)$ to $\left[\mathrm{C}_{2} \mathrm{Py}\right]\left[\mathrm{NTf} \mathrm{f}_{2}\right](\alpha 0.60)^{40}\left(\mathrm{~V}_{\mathrm{m}}\right.$ 253.80), there is a reduction of only two carbons from the alkyl chain but this increases the hydrogen bonding of the ionic liquid such that $\left[\mathrm{C}_{2} \mathrm{Py}\right]\left[\mathrm{NTf}_{2}\right]$ can only form weak unstable to inversion gel like materials at 4 wt. \% gelator 2. $\left[\mathrm{C}_{4} \mathrm{Py}\right]\left[\mathrm{NTf} \mathrm{f}_{2}\right]$ however can form a stable to inversion gel at 2 wt. \% 2. It appears that Increasing the chain length on imidazolium can inhibit gelation. $\mathbf{2}$ can gel [ $\left.\mathrm{C}_{6} \mathrm{MIM}\right]\left[\mathrm{NTf}_{2}\right]$ at $2 \mathrm{wt}$ \% but $\left[\mathrm{C}_{8} \mathrm{MIM}\right]\left[\mathrm{NTf}_{2}\right]$ or $\left[\mathrm{C}_{12} \mathrm{MIM}\right]\left[\mathrm{NTf}_{2}\right]$ do not form gels at 2 wt. \%. they require $4 \mathrm{wt}$. \% of gelator. One possible explanation is that, as the hydrophobic nature of the cation increases, it is able to disrupt the hydrogen bonding of the LMWGs. Higher wt. \% of the LMWG does allow gelation, possibly due to formation of a larger/stronger 3D lattice which can overcome the increased hydrophobicity. Despite the disruption caused by the longer alkyl chain length it may be beneficial in some cases. Hanabusa et $a I^{12}$ found that LMWGs which gelled organic solvents were often insoluble in ionic liquids. The longer alkyl chain may increase solubility of the LMWG in the ionic liquid due to an increase in $\pi^{*}$ character which is largely associated with stabilise solvated species. ${ }^{19,22}$ As noted previously, dissolution of the LMWG is essential for gelation so the longer alkyl chain may facilitate gelation.

In these imidazolium ionic liquids ([ $\left.\left.\mathrm{C}_{6} \mathrm{MIM}\right]\left[\mathrm{NTf} f_{2}\right],\left[\mathrm{C}_{8} \mathrm{MIM}\right]\left[\mathrm{NTf} \mathrm{f}_{2}\right]\left[\mathrm{C}_{12} \mathrm{MIM}\right]\left[\mathrm{NTf} \mathrm{f}_{2}\right]\right)$, the steric bulk only increases in one axis of 3D space (Fig. 7). Steric bulk of the ionic liquid becomes more inhibitive to gelation when it extends in all axes of 3D space. We have observed this by comparing [EMIM][NTf $\left.{ }_{2}\right]$ $\left(\mathrm{V}_{\mathrm{m}}\right.$ 257.44) and [BMIM] $\left[\mathrm{NTf}_{2}\right]\left(\mathrm{V}_{\mathrm{m}}\right.$ 291.22) with [EMIMIM] $\left[\mathrm{NTf} \mathrm{f}_{2}\right]\left(\mathrm{V}_{\mathrm{m}} 272.04\right)$ and [BMIMIM] $\left[\mathrm{NTf}_{2}\right]\left(\mathrm{V}_{\mathrm{m}}\right.$ 305.2). [EMIMIM] $\left[\mathrm{NTf}_{2}\right]$ and [BMIMIM] $\left[\mathrm{NTf}_{2}\right]$ are extended perpendicular to the alkyl chain by only one carbon. Despite having slightly lower $\alpha$ values $\left(0.42^{41}\right.$ and $\left.0.38^{22}\right)$ they formed gels at 4 wt. \% 2 but when the concentration was reduced to $2 \mathrm{wt}$. \% only gel-like precipitates (not stable to inversion) were formed (ESI tables S1 and S2). Despite having a higher molar volume than both [EMIMIM] $\left[\mathrm{NTf}_{2}\right]$ and $[\mathrm{BMIM}]\left[\mathrm{NTf} f_{2}\right],\left[\mathrm{C}_{6} \mathrm{MIM}\right]\left[\mathrm{NTf}_{2}\right]$ can form a gel with lower wt. \% 2. Potentially this 
is a result of the alkyl chain of $\left[\mathrm{C}_{6} \mathrm{MIM}\right]\left[\mathrm{NTf}_{2}\right]$ extending in one axis of 3D space whereas

[EMIMIM] $\left[\mathrm{NTf}_{2}\right]$ and [BMIM][NTf $\left.f_{2}\right]$ expand in all axes of 3D space. This observation is further underlined when considering ammonium and phosphonium based ionic liquids. When there was large steric bulk in one direction, such as with $\left[\mathrm{N}_{2228}\right]\left[\mathrm{NTf}_{2}\right]\left(\mathrm{V}_{\mathrm{m}} 389.42\right)$, a 2 wt. \% gelator 2 mixture could form a gel. However when the steric bulk increased in several directions, such as with $\left[\mathrm{N}_{1888}\right]\left[\mathrm{NTf}_{2}\right]\left(\mathrm{V}_{\mathrm{m}}\right.$ 600.79), $2 \mathrm{wt}$. \% formed a solution and $4 \mathrm{wt}$. \% 2 was required to form a gel. $\mathrm{A}$ similar result was seen comparing $\left[\mathrm{P}_{4448}\right]\left[\mathrm{NTf}_{2}\right]\left(\mathrm{V}_{\mathrm{m}} 504.81\right)$, which formed a gel with $5 \mathrm{wt}$. \% 2 , and $\left[\mathrm{P}_{66614}\right]\left[\mathrm{NTf}_{2}\right]\left(\mathrm{V}_{\mathrm{m}} 714.02\right)$ which did not gel at $10 \mathrm{wt}$. \% 2. Figures 7 and 8 show a schematic for the possible mechanism for these occurrences. Ionic liquids with bulk in one direction may be able to fit without disrupting the supramolecular network and thus preventing gelation. Ionic liquids with bulk that extends in more than one, or in all directions, push the gelator molecules far apart, preventing them from forming a network and therefore preventing gel formation.

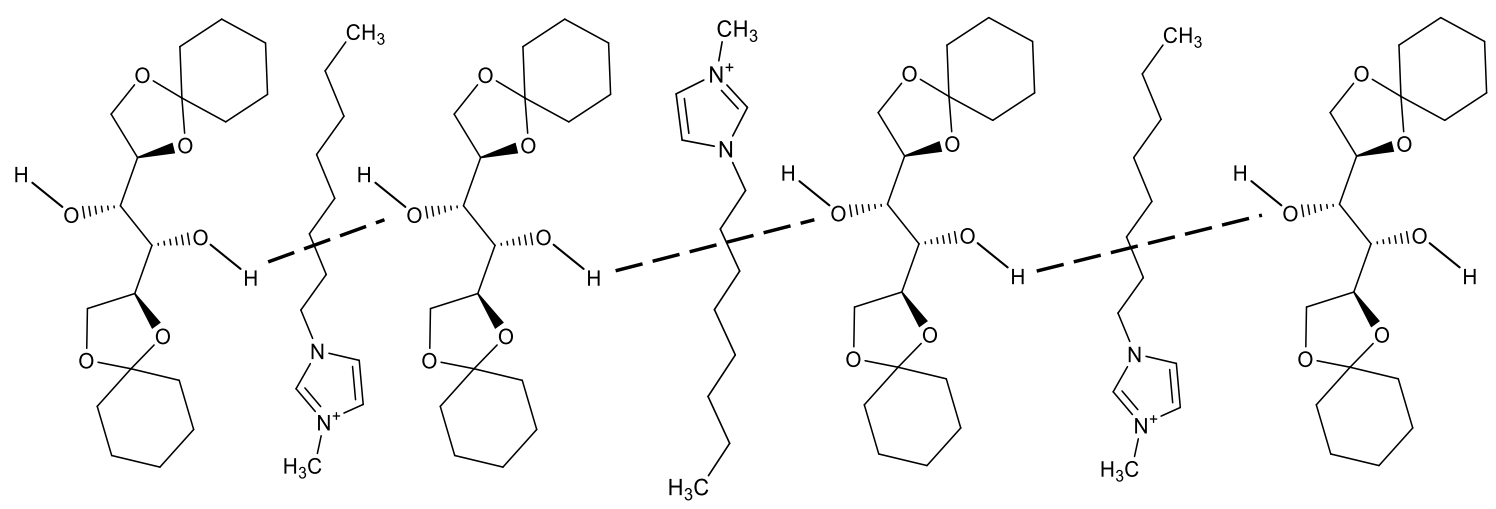

Fig. 7: Schematic showing how long chain cations could fit inside the solid network of 


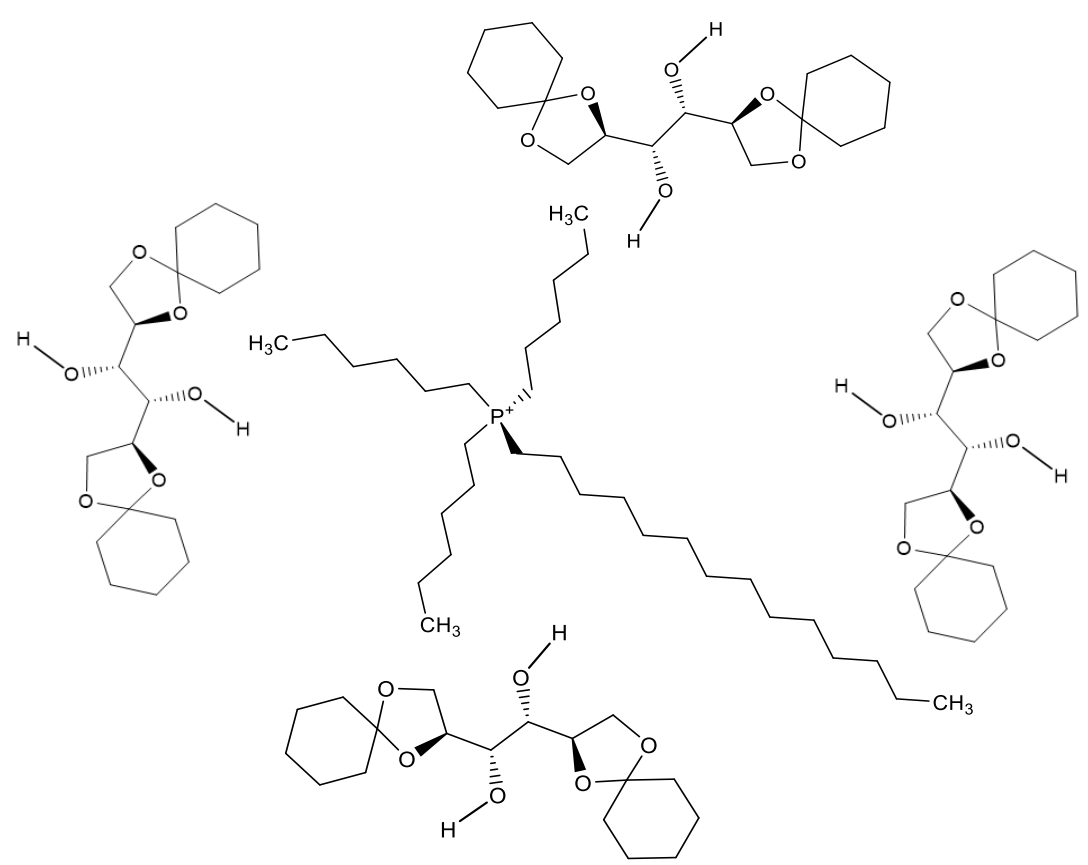

Fig. 8. Schematic, showing how a bulky cation could disrupt the formation of the solid network of the gel.

To our knowledge the influence of sterics on the gelation of LMWGs has not been previously noted, this is presumably because most gelation work has been carried out in organic solvents. These may have long chains or bulky ring systems but steric bulk rarely extends in more than one direction, meaning their steric bulk does not have a significant effect on gelation. Low molecular weight organics that are bulky in all directions, such as triphenylmethane are often solids.

Cations




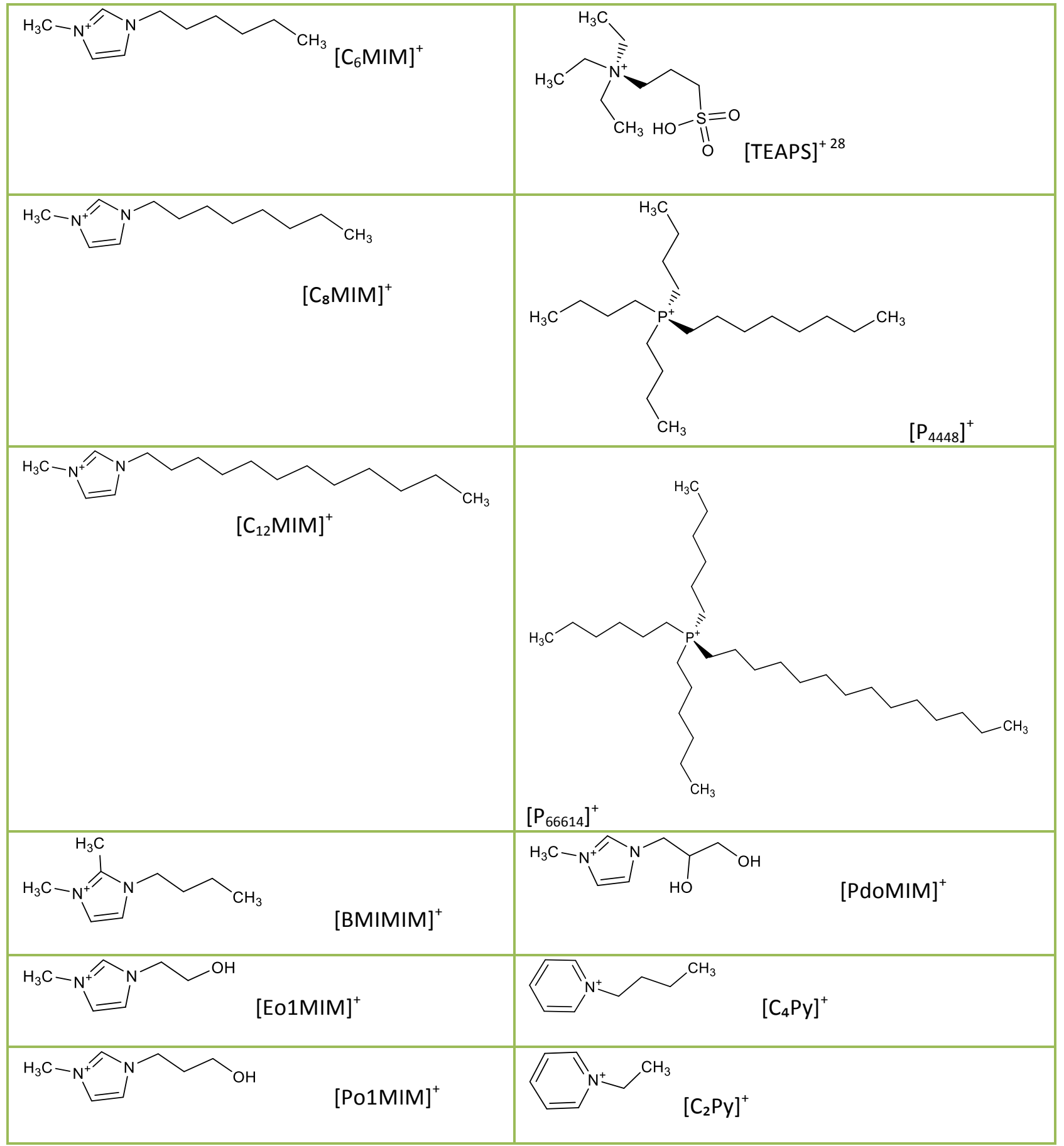

Fig. 9. Range of cations used.

\section{Effect of ion combinations}

The hydrogen bonding abilities of the ions are assessed separately and we observed that, as the ionic liquid is in excess, a strongly hydrogen bond donating cation or a strongly hydrogen bond accepting anion saturates the LMWG and prevents it forming a 3D network and hence, a gel. It has already been noted how the main interactions in an ionic liquid are ionic, however there is also a substantial hydrogen bonding component as well. We included in our screening ionic liquids in which 
the cation is a strong hydrogen bond donor and the anion is a strong hydrogen bond acceptor. For example $[\mathrm{PdoMIM}][\mathrm{Cl}]$ has an $\alpha$ value of 1.12 and a $\beta$ value of $0.99 ;^{42}$ these values are comparable to ionic liquids which did not gel eg. [Eo1MIM] $\left[\mathrm{NTf}_{2}\right](\alpha$ 1.14), [BMIM] $\mathrm{Br}(\beta$ 0.87) and [BMIM][OAc] ( $\beta$ 0.85). However this IL was shown to form a gel at 3 wt.\% gelator 2 . Looking at the values in isolation could lead to the assumption that this IL would not form a gel. However the occurrence of gelation would indicate that the anion and the cation are hydrogen bonding to each other in preference to the gelator molecules allowing the gelator to form a 3D network. The $\alpha$ and $\beta$ values must be closely matched to observe this effect. We therefore propose that minimising the interaction of the ions with the gelator leads to stable gel formation with gelator 2 .

\section{Contribution of the 3 gelators, LMWG Comparisons.}

In the crystal structure of gelator $\mathbf{1}^{25}$ there are two possible hydrogen bonds between ring oxygens and acidic hydrogens, of $1.6 \AA$, a length associated with medium strength hydrogen bonds. ${ }^{43}$ Overall $\mathbf{1}$ is a poorer LMWG than $\mathbf{2}$ (ESI Tables S2 and S3). Often $\mathbf{1}$ required a higher wt. \% than $\mathbf{2}$ in order to form a gel (e.g with [EMIM][NTf $f_{2}$, [EMIMIM][NTf $\left.{ }_{2}\right]$ ) and [BMIMIM][NTf $\left.\left.f_{2}\right]\right)$. With [PdoMIM][CI], 1 does not form a gel at any concentration tested whereas with $\mathbf{2}$ it forms a gel at $3 \mathrm{wt}$. \%. An interesting observation is seen with [TEAPS] [NTf 2 ], an acidic ionic liquid, ${ }^{28}$ where 1 did not gel at 4 wt. \% but $\mathbf{2}$ did. If the interactions between the molecules of $\mathbf{1}$ are due to ring oxygens and acidic hydrogens, ${ }^{25}$ then the acidic nature of $[$ TEAPS $]\left[\mathrm{NTf}_{2}\right]^{28}$ would allow it to interact with the molecules of 1, preventing the LMWG molecules from interacting with each other to form a gel. 1, like $\mathbf{2}$, is unable to form gels with the strongly hydrogen bond accepting ionic liquids. Unexpectedly, in the case of phosphonium ionic liquids, $\mathbf{1}$ appears to be a more efficient LMWG than $\mathbf{2}$. Gelator $\mathbf{1}$ formed a gel with $\left[\mathrm{P}_{4448}\right]\left[\mathrm{NTf} f_{2}\right]$ at $4 \mathrm{wt}$. \% when 2 required $10 \mathrm{wt}$ \% and $\mathbf{1}$ gelled $\left[\mathrm{P}_{66614}\right]\left[\mathrm{NTf}_{2}\right]$ at $10 \mathrm{wt}$ \% whereas $\mathbf{2}$ did not form a gel. This adds further evidence to our observations that interaction between the IL and the gelator inhibits gel formation with $\mathbf{2}$ as $\mathbf{2}$ could interact with the IL through van der Waals' interactions. A more straightforward set of comparisons can be made between $\mathbf{2}$ and $3^{26}$ (Fig. 2). Both of these LMWGs are based on a D-mannitol backbone 2 has two cyclohexyl ketal groups while $\mathbf{3}$ has two isopropyl ketal groups. It might have been assumed that the larger cyclohexyl groups would hinder aggregation of the gelator molecules and therefore prevent gelation. Here the opposite effect was observed. Generally $\mathbf{2}$ is able to gel ionic liquids at lower wt. \%, compared to the smaller 3 . This is the case for [EMIM[NTf $f_{2}$, [BMIM][NTf $]$, [EMIMIM][NTf $f_{2}$, [BMIMIM] $\left[\mathrm{NTf}_{2}\right]$ and $\left[\mathrm{C}_{4} \mathrm{Py}\right]\left[\mathrm{NTf}_{2}\right]$. Each of these ionic liquids were gelled by $2 \mathrm{wt}$. \% of $\mathbf{2}$. In contrast $2 \mathrm{wt}$. \% of $\mathbf{3}$ exclusively formed solutions and $4 \mathrm{wt}$. \% of $\mathbf{3}$ was required to form a gel states. This effect has also been observed when using $\mathbf{2}$ and $\mathbf{3}$ with organic solvents (organogels). ${ }^{26} \mathrm{An}$ 
explanation could be that the larger cyclohexyl units prevent conformational freedom which improves preorganization of the gelator molecules, an effect which has been reported to aid gelation. ${ }^{44}$ This allows for easier aggregation of the molecules in solution to form a 3D network. 3 is less bulky so has more conformational freedom allowing the 3D network it forms to be broken up more easily than $\mathbf{2}$. There would also be increased van der Waals' interactions which, may have a significant effect in LMWG aggregation, particularly for larger molecules.

\section{General experimental details}

\section{LMWG}

Three LMWGs gelators were synthesised as per literature procedures. ${ }^{25,26}$ Specific synthetic methodology and characterisation of 1, $\mathbf{2}$ and $\mathbf{3}$ are included in the Electronic Supplementary Information (ESI S3 and S4).

\section{Standard gelation tests method}

An accurately weighed amount of LMWG ( 0.02 g) was added to a GC vial. lonic liquid was pipetted in with a Pasteur Pipette according to the weight \% of the test; e.g. for $10 \mathrm{wt} . \%$ of LMWG, $\sim 0.2 \mathrm{~g}$ ionic liquid was added to $\sim 0.02 \mathrm{~g}$ of LMWG. The GC vial was sealed and placed in an ultrasound bath and sonicated until the solid dissolved (up to a maximum of one hour). The sample was then heated to $95^{\circ} \mathrm{C}$ for between 30 minutes and 1 hour (until the solid had dissolved). The sample was then left to cool and observed for gelation upon cooling. If no gelation occurred after several days, the sample was reheated for 1 hour and allowed to cool again. Gelation was deemed successful if the sample was stable to inversion after several days. The wt. \% of LMWG were 2, 4, 5 and 10. Ionic liquids were synthesised in house or bought, synthetic details and characterisation can be found in the Electronic Supplementary Information (ESI) along with Gel Photos, Gel testing, experimental details, IL synthesis, TGA, DSC, NMR, optical microscopy, XRD and IL abbreviations.

\section{Conclusions}

The formation of a wide range of molecular ionic liquid gels has been achieved using cheap, sustainable, and easily synthesised sugar-based LMWGs. 21 ionic liquids were found to form gels with 3 such gelators. This class of reversible gels are of significant interest in electrochemical applications. ${ }^{13,14}$ The ionic liquids' thermal stability was improved by the addition of the LMWGs. Gels were successfully formed with imidazolium, pyridinium, phosphonium and ammonium based ionic liquids. As the cation size was increased, the wt. \% of LMWG required for gel formation needed to be larger. The hydrogen bonding ability of the ionic liquids was found to greatly influence 
gelation. In the case of the cation, as the value for $\alpha$ was increased, corresponding with an increased strength of hydrogen bond donation, a higher wt. \% of gelator was required to form stable gels. No gel was formed when the anion was strongly hydrogen bond accepting (with a large $\beta$ value). Anions with the lowest $\beta$ values $\left[\mathrm{BF}_{4}\right]^{-},\left[\mathrm{NTf}_{2}\right]^{-}$and $\left[\mathrm{PF}_{6}\right]^{-}$, with values of $0.37,0.23$ and 0.21 respectively ${ }^{22,33}$ formed gels at the lowest concentration of gelator $\mathbf{2}(2 \mathrm{wt}$. \%). It was also noted that in ionic liquids where the cation was a strong hydrogen bond donor and the anion a strong hydrogen bond acceptor there was less disruption to gel formation. This prompts caution as the investigator should not solely look at the values for $\alpha$ or $\beta$ in isolation. In this study we observe that less interaction between the IL and the gelator appears to promote more successful gel formation. The size of the cation has a lesser effect on gelation than hydrogen bonding interactions. Ionic liquids that extend in many directions appear to disrupt gelation more than a single long alkyl chain. All 3 LMWGs tested $(\mathbf{1 , 2}$ and 3) exhibited ability to gel ionic liquids. Gelator $\mathbf{2}$ was the most inclusive LMWG for the ionic liquids tested. This is partly due to a decrease in polarity, a decrease of conformational freedom, and an increase in van der Waals' interactions. Having a greater understanding of the strengths and limitations of low molecular weight ionic liquid gel formation could support the design of functionalised low molecular weight ionic liquid gels for use in chemocatalysis and biocatalysis, environmental clean up, metal recovery, pharmaceuticals, and electrochemical devices such batteries, capacitors and solar cells.

\section{Associated Content}

Electronic supplementary information (ESI). Details of: Materials and methods, Gel Photos, Gel testing, experimental details, IL synthesis, TGA, DSC, NMR, optical microscopy, XRD, and IL abbreviations.

\section{Acknowledgments}

Dr. A. C. Marr for valuable discussions and continued support. Queen's University Belfast, School of Chemistry and Chemical Engineering.

\footnotetext{
${ }^{1}$ P. Dastidar, Chem. Soc. Rev., 2008, 37, 2699-2715.

${ }^{2}$ P. Terech, R. G. Weiss, Chem. Rev., 1997, 97, 3133-3160.

${ }^{3}$ A. Friggeri, O, Gronwald, K. J. C. van Bommel, S. Shinkai, D. N. Reinhouldt, J. Am. Chem. Soc., 2002, 124, 10754-10758.

4 J. W. Steed, Chem. Commun., 2011, 47, 1379-1383.

${ }^{5}$ B. O. Okesola, D. K. Smith, Chem. Soc. Rev., 2016, 45, 4226-4251.

${ }^{6}$ Y. Lan, M. G. Corrandi, R. G. Weiss, S. R. Raghavan, M. A. Rogers, Chem. Soc. Rev., 2015, 44, 6035-6058.

${ }^{7}$ M. Raynal, L. Bouteiller, Chem. Commun., 47, 2011, 8271-8273.

${ }^{8}$ K. K. Diehn, H. Oh, R. Hashemipour, R. G. Weiss and S. R. Raghavan, Soft Matter, 2014, 10, 2632-2640.

${ }^{9}$ N. Kimizuka and T. Nakashima, Langmuir, 2001, 17, 6759-6761.

${ }^{10}$ A. Ikeda, K. Sonoda, M. Ayabe, S. Tamaru, T. Nakashima, N. Kimizuka and S. Shinkai, Chem. Lett., 2001, 30, 1154-1155.
} 
${ }^{11}$ W. Kubo, S. Kambe, S. Nakade, T. Kitamura, K. Hanabusa, Y. Wada and S. Yanagida, J. Phys. Chem. B, 2003, 107, 4374-4381.

12 K. Hanabusa, H. Fukui, M. Suzuki, H. Shirai, Langmuir, 2005, 21, 10383-10390.

${ }^{13}$ B. A. Voss, J. E. Bara, D. L. Gin and R. D. Noble, Chem. Mater., 2009, 21, 3027-3029.

${ }^{14}$ L. Tan, X. Dong, H. Wang and Y. Yang, Electrochem. Commun., 2009, 11, 933-936.

${ }^{15}$ L. Tao, Z. Huo, Yo Ding, Y. Li, S. Dai, L. Wang, J. Zhu, X. Pan, B. Zhang, J. Yao, M. K. Nazeeruddin and M. Grätzel, J. Mater. Chem. A, 2015, 3, 2344-2352.

${ }^{16}$ T. Tu, X. Bao, W. Assenmacher, H. Peterlik, J. Daniels and K. H. Dötz, Chem. Eur. J., 2009, 15, 1853-1861.

${ }^{17}$ P. C. Marr, A. C. Marr, Green Chem., 2016, 18, 105-128.

${ }^{18}$ P. A. Hunt, C. R. Ashworth, R. P. Matthews, Chem. Soc. Rev., 2015, 44, 1257-1288.

${ }^{19}$ M. J. Kamlet, J. L. M. Abboud, M. H. Abraham, R. W. Taft., J. Org. Chem., 1983, 48, 2877-2887.

${ }^{20}$ L. Crowhurst, P. R. Mawdsley, J. M. Perez-Arlandis, P. A. Slater and T. Welton, Phys. Chem. Chem. Phys., 2003, 5, 2790-2794.

${ }^{21}$ A. Oehlke, K. Hofmann and S. Spange, New J. Chem., 2006, 30, 533-536.

${ }^{22}$ M. A. Ab Rani, A. Brant, L. Crowhurst, A. Dolan, M. Lui, N. H. Hassan, J. P. Hallett, H. Niedermeyer, J. M. Perez-Arlandis, Michael Schrems, T. Welton, R. Wilding, Phys. Chem. Chem. Phys., 2011, 13, 16831-16840.

${ }^{23}$ F. D’Anna, P. Vitale, F. Ferrante, S. Marullo, R. Noto, ChemPlusChem, 2013, 78, 331-342.

${ }^{24}$ G. O. Lloyd, J. W. Steed, Nat. Chem., 2002, 1, 437-422.

${ }^{25}$ S. J. Craythorne, C. L. Pollock, A. J. Blake, M. Nieuwenhuyzen, A. C. Marr, P. C. Marr, New J. Chem, 2009, 33, 479-483.

${ }^{26}$ A. Vidyasagar, K. Handore, K. M. Sureshan, Angew. Chem. Int. Ed., 2011, 50, 8021-8024.

${ }^{27}$ P. Duan, H. Cao, L. Zhang, M. Liu, Soft Matter, 2014, 10, 5428-5448.

${ }^{28}$ Y. Wang, V. Ulrich, G. F. Donnelly, F. Lorenzini, P. C. Marr and A. C. Marr, ACS Sustainable Chem. Eng., 2015, 3, 792-796.

${ }^{29}$ K. S. Suslick, Sci. Am., 1989, 260, 80-86.

30 S. R. Raghavan, B. H. Cipriano, Molecular Gels, ed. R. G. Weiss, P. Terech, Springer, Amsterdam, 2005, ch. 8, pp. 251.

31 K. Nishinari, Colloid Polym. Sci., 1997, 275, 1093-1107.

${ }^{32}$ K. M. Bothwell, P. C. Marr, ACS Sustainable Chem. Eng., 2017, 5, 1260-1263.

${ }^{33}$ C. Chiappe, D. Pieraccini, J. Phys. Chem. A, 2006, 110, 4937-4941.

${ }^{34}$ R. Lungwitz, M. Friedrich, W. Linert, S. Spange, New J. Chem., 2008, 32, 1493-1499.

${ }^{35}$ A. Mota, J. P. Hallet, M. L. Kuznetsov, I, Correia, Phys. Chem. Chem. Phys., 2011, 13, 15094-15102.

${ }^{36}$ S. P. M. Ventura, C. M. S. S. Neves, M. G. Freire, I. M. Marrucho, J. Oliveira, J. A. P. Coutinho, J. Phys. Chem. $B, 2009,113,9304-9310$.

${ }^{37}$ A. Efimova, G. Hubrig, P. Schmidt, Thermochim. Acta., 2013, 573, 162-169.

${ }^{38}$ P. A. Hunt, B. Kirchner, T. Welton, Chem. Eur. J., 2006, 12, 6762-6775.

${ }^{39}$ Y. Wu, T. Sasaki, K. Kazushi, T. Seo, K. Sakurai, J. Phys. Chem. B, 2008, 112, 7530-7536.

${ }^{40}$ A. Tsrumaki, S. Tajima, T. Iwata, B. Scrosati, H. Ohno, Electrochim. Acta, 2015, 175, 13-17.

${ }^{41}$ S. Coleman, R. Byrne, S. Minkovska, D. Diamond, Phys. Chem. Chem. Phys., 2009, 11, 5608, 5614.

${ }^{42}$ C. Chiappe, C. S. Pomelli, S. Rajamani, J. Phys. Chem. B, 2011, 115, 9653-9661.

${ }^{43}$ J. W. Steed, J. L. Atwood, Supramolecular Chemistry: a concise introduction, Wiley, Chichester, 2000, ch. 1.

${ }^{44}$ O. Gronwald, S. Shinkai, Chem. Eur. J., 2001, 7, 4328-4334. 